\title{
The information conveyed by varying the dimensions of features in human outline faces
}

\author{
JOHN L. BRADSHAW 1 \\ MO^ASH UNIVER.SITY
}

\begin{abstract}
Outline drawings of human faces were prestnted for rating as to a number of dichotomous attributes, while the dimensions of the four constituent features were varied svstematically. It was found that people act in a regular and predictable fashion in atributing characteristics to certain of these features. When independently signific ant features appcar in combination. there is a law ful increase in such characterizing responses. Subsidiar findings related to a halo effect between certain attributes. differential emplos ment of some attributes, and a difference in overall strength of effect hetween certain features.
\end{abstract}

The human face is largely unifue in its laal role of communication and identification. Variations in the relative positions of the various components or features assist both functions, both of which involve information transmission.

The question of facial identification relates particularly to problems of pattern recognition. Other aspects include the innateness/learning problem. stimulus importance and meaning, and part-whole configurations. For example. Hershenson et al (1967) studied the orienting response of human neonates to outline face drawings, both normal and scrambled.

The role of the face in communication, moreover, can be studied within two further contexts. Problems of personperception proper occupy one field of study. while related to this are questions as to how we operate when attempting to judge a person's character from his features. These anproaches overlap in, for example, the studies of Secord (1958). The face was seen to reflect or conceal emotional states, desires, feelings, and intentions. As a result, people tended to have certain judgmental stereotypes, relating features to character differences. Examples included bowed lips and conceit, thick lips and feminine sexuality, high foreheads and intelligence.

Similar studies were reviewed earlier by Sheldon and Tucker (1940), where in general no correlation was found between such judged traits and independent assessments. Nevertheless, prior to this, Brunswik and Reiter (1937) found consistencies in judgments of intelligence, age, and character when Ss viewed outline drawings of faces with alterations in the dimensions of certain features. Brooks and Hochberg (1960) looked at the effects of altering eye position on judgmental qualities such as cuteness. Similarly, Secord and Muthard (1955) examined the extent to which such factors as grooming, the wearing of glasses, and lip thickness affect the judgment of traits. The question remains of the extent to which such findings can carry over from schematic drawings to real-life situations (cf. Samuels, 1939).

Brunswik and Reiter (1937) in their study had varied eye-width, brow-height, and nose and mouth positions in their outline drawings of faces. Judgments were made for intelligence, mood, occupation, age, etc., using a nonEnglish-speaking population. In view of the comparative inaccessibility of this pioneer study, the need to use more systematically varying stimuli, and possible alternative approaches in quantifying and comparing the data. a similar experiment was performed. It was hoped to be able to determine the extent to which human Ss could process various feature combinations in an informational sense. That is to say, if certain features were found independently to affect judgments ahout attributes. what happened when they appeared in combination?

\section{METHOD}

Outine laces were constructed with systematically varying features. such that the eycs could he fas apart or close together. high or low. The nose could be long or short and the mouth wid: or narrow. Two extreme examples are given in Fig. 1. This provided a total of 16 possible combinations $\left(2^{4}\right)$. In all cases the distance between the bottom of the nose and the mouth, and the top of the nose and the axis of the cyes was kept constant. Varied eye-height meant shifting all the features up or down the face and was in fact particularly reflected in forehead height. These stimuli were drawn from prepared templates onto cards, the vertical axis of the facc measuring $43 / 4$ in., the rest heing to scale as shown in Fig. 1 .

The Ss were 41 first-year psychology students. 27 males and 14 females. The cards were shuffled and arranged in a closed. hollow square upon a board. In the center of the board were written the seven dichotomous attributes or dimensions for judgment male/female, young/old, happy/sad, stupid/clever, mean/generous, trustworthy/untrustworthy, wise/foolish. Each card had to be rated dichotomously for all seven attributes. The Ss were encouraged to start at any point on the square and work systematically around. It was considered important that all 16 examples continue to be present throughout so that a comparison could be made in each case against all other members of the ensemble. In Table 1 can be seen the scheme of the features and the card identification number.

The seven attributes for rating were chosen somewhat arbitrarily. Two attributes, age and sex, were thought to be the two most common objective dimensions whereby we categorize each other. The other five were thought to be frequently used judgments relating to personality characteristics. Despite their overt similarity, it was thought that the implied difference between stupid/clever and wise/foolish, in terms of intelligence vs knowledge, might prove of interest. It was considered probable that there would be further overlaps, or halo effects, between other attributes.
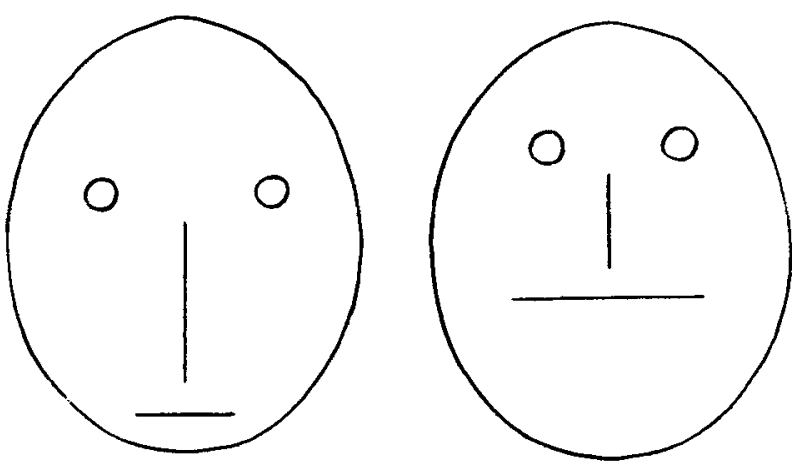

Fig. 1. Examples of two outline faces, one with eyes low. eyes wide. nose long. and mouth narrow, and the other with converse features. 
Table 1

Summarized Schema of the Features of the 16 Different Stimulus Cards, Together with Identification Number

\begin{tabular}{|c|c|c|c|c|}
\hline 1 & Eyes High & Eyes Wide & Nose Short & Mouth Narrow \\
\hline 7 & Eyes High & Eyes Wide & Nose Short & Mouth Wide \\
\hline 6 & Eyes High & Eyes Wide & Nose Long & Mouth Narrow \\
\hline 15 & Eyes High & Eyes Wide & Nose Long & Mouth Wide \\
\hline 10 & Eyes High & Eyes Narrow & Nose Short & Mouth Narrow \\
\hline 9 & Eyes High & Eyes Narrow & Nose Short & Mouth Wide \\
\hline 3 & Eyes High & Eyes Narrow & Nose Long & Mouth Narrow \\
\hline 5 & Eyes High & Eyes Narrow & Nose Long & Mouth Wide \\
\hline 8 & Eyes Low & Eyes Wide & Nose Short & Mouth Narrow \\
\hline 12 & Eyes Low & Eyes Wide & Nose Short & Mouth Wide \\
\hline 16 & Eyes Low & Eyes Wide & Nose Longe & Mouth Narrow \\
\hline 13 & Eyes Low & Eyes Wide & Nose Long & Mouth Wide \\
\hline 14 & Eyes Low & Eyes Narrow & Nose Short & Mouth Narrow \\
\hline 11 & Eyes Low & Eyes Narrow & Nose Short & Mouth Wide \\
\hline 2 & Eyes Low & Eyes Narrow & Nose Long & Mouth Narrow \\
\hline 4 & Eyes Low & Eyes Narrow & Nose Long & Mough Wide \\
\hline
\end{tabular}

\section{RESULTS}

Table 2 presents the totals, over the 16 stimulus cards and 41 Ss, for the seven attributes. Data for only one of each pair is provided as the pair taken together sums to 41 . It can be seen that in no category is there an even distribution of scores; overall, there are more allocations to male than to female, more to young than to old, etc. There is, in fact, a descending order of imbalance from wisdom, through sex, stupidity, trustworthiness, happiness, and generosity, to age. Reference to the normal approximation to the binomial probability distribution indicates that all these imbalances are statistically significant at $p<.05$.

Table 3 presents the totaled raw scores of each of the two members of each feature pair when broken down by attribute. From these, the differences are calculated by subtraction. This figure is the same irrespective of whether it is calculated upon, say, total male scores or total female scores. An indication is also given when this difference between the two distributions of scores reaches significance. Use was made of the fact that when an expected and an obtained score in a binomial distribution differ by a certain number of standard deviations, the significance of that difference can readily be obtained by reference to a table of the,probability integral.

It can be seen that ey-height, that is, forehead-height, contributes most, and eye'width least, to the Ss' perception of attributes. Similarly, there is a descending order of magnitude, starting at happiness, passing through generosity, age, sex, trutworthiness, stupidity, and ending at wisdorm, with the perceived attributes. Together, these two trends would imply that eye-height and happiness interact the most strongly and eye-width and wisdom the least. The negative sign in the differences can be made to disappear, as in Table 4 , by reversing the polarity of either the feature or the attribute.

Consequently, in Table 4 are presented those difference scores which were found significant in Table 3 , together with one attribute (stupid) which is presented for comparison, as none of its components were found significant. The difference scores are presented in three columns, labeled 8,8 cards, 4,4 cards, and 2,2 cards. In the first column, the total difference scores obtained from Table 3 are corrected for number of contributing cards. As single features are being individually compared, there were two sets of eight relevant cards, one set containing the particular feature (e.g., eyes high) and one set containing the converse (eyes low). Consequently, a difference score corrected for number of contributory cards is obtained by dividing the original score by 8 .

Similarly, in the second column, the combined effect of two independently significant features is presented (e.g., eyes high together with nose short). The difference score is now derived from two sets of four cards, instead of eight. Consequently, a correction is applied by dividing the obtained total difference score by 4 .

When three features independently signify an attribute, their isolated corrected difference scores appear in the first column, their combined effects taken two at a time appear in the second, and their combined effects, taken all three together, appear in the third. By now, of course, there are only two cards which contain all three relevant features and two which contain their converse. Consequently, the total difference score for these two cards is corrected by dividing by 2. As the figures indicate, these two cards are the most powerful indicators of the particular feature as they contain all the relevant features together. There is no 1,1 card category in Table 3 as in no case was eye width found to indicate significantly any attribute.

Figure 2 graphs the averaged points obtained from each grouping in Table 4. Also given are the three theoretical plots which would be obtained were human Ss perfectly systematic in their responses to combinations of features. A theoretical 4,4 plot is calculated, even though none were found

Table 2

Raw Scores; for Each Attribute, only One of Each Complementary Pair is Given, as Each Pair Sums to 41

\begin{tabular}{lccccccc}
\hline Card & Male & Young & Happy & Stupid & Generous & Trustworthy & Wise \\
\hline 1 & 30 & 30 & 34 & 30 & 25 & 25 & 12 \\
7 & 27 & 29 & 40 & 34 & 38 & 30 & 8 \\
6 & 14 & 29 & 19 & 16 & 18 & 24 & 26 \\
15 & 36 & 13 & 18 & 26 & 26 & 21 & 18 \\
10 & 20 & 21 & 31 & 27 & 24 & 23 & 16 \\
9 & 32 & 16 & 37 & 28 & 31 & 24 & 10 \\
3 & 24 & 30 & 24 & 11 & 18 & 26 & 28 \\
5 & 32 & 25 & 29 & 22 & 32 & 28 & 15 \\
8 & 12 & 32 & 17 & 9 & 30 & 30 & 24 \\
12 & 22 & 22 & 20 & 12 & 29 & 24 & 22 \\
16 & 17 & 16 & 0 & 27 & 11 & 23 & 12 \\
13 & 28 & 9 & 4 & 29 & 10 & 14 & 9 \\
14 & 12 & 35 & 21 & 18 & 21 & 25 & 18 \\
11 & 25 & 18 & 6 & 22 & 18 & 11 & 18 \\
2 & 31 & 12 & 0 & 23 & 9 & 15 & 18 \\
4 & 23 & 12 & 0 & 32 & 11 & 16 & 14 \\
Sum & 385 & 349 & 300 & 366 & 351 & 359 & 268 \\
Complementary & 271 & 307 & 356 & 290 & 305 & 297 & 388 \\
Mean 328 & Total & 656 & & & & & \\
\hline
\end{tabular}




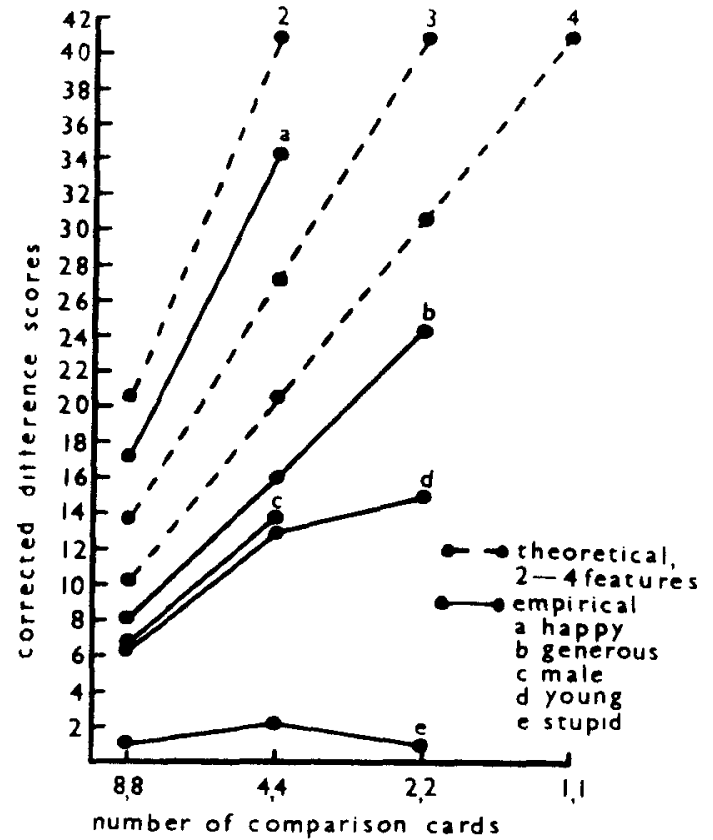

Fig. 2. Graph of possible and actual difference scores, corrected for number of stimulus exemplars, when two or more features together characterize an attribute.

empirically. These were calculated on the assumption that, for example, with three relevant features the following situation would obtain. When all three features were present together, all 41 Ss would assign the appropriate attribute to that card. When all three features were absent, that is, present in converse form, all 41 Ss would assign the converse of the attribute to that card. When two of the three features were present, and one was opposed, the score would be reduced by one-third, and so on, on a pro rata basis. This makes two assumptions. One is that all features would contribute equally, if at all, towards an attribute. Reference to Table 4 shows that this is not strictly true. The second assumption is that the population of scores would reflect the individual's level of uncertainty. That is to say, given the presence of two out of three features, an individual would be two-thirds tempted to opt for that particular attribute, and this would be reflected in the total distribution of scores. The evidence from Fig. 2 strongly supports this view. The theoretical plot shows that every time the number of comparison cards is halved, the original corrected difference score as at 8,8 should be given a constant uncrement. This increment, equal to the original score at 8.8 . is itself determined by the total number of features which can together characterize that attribute. The empirical data can be seen to follow this rule exactly. The only exceptions are a drop in the 2,2 figure for young, and the nonsignificant curve for stupid, which was merely provided for comparison. Thus, as the information in the stimulus increases through combination of relevant features, there is a corresponding linear increase to be seen in the corrected difference scores.

In Table 5 evidence can be seen of a strong "halo effect." It was considered possible that when a $S$ had, for example, attributed "young" to a stimulus, this would tend to induce related judgments of "happy," "generous," etc., rather than "sad" and "mean." Consequently, the data from each $S$ were analyzed for all 21 possible attribute-pairs into the number of instances of, for example, male/old, female/young vs male/young, female/old. In Table 5 both the observed scores and the expected chance scores are given, the latter obtained by calculation fram the ratios given at the bottom of Table 2 . In Table 5 only the data for half the combination are given, viz male/old. female/young, instead of also male/young, female/ old. For the latter halves, data can be obtained by subtraction from 656 . It can be seen that the score for the greater half has been given in each case, i.e., the score that indicates the direction of the halo effect. It is evident that the effect is quite strong; young is linked with happy, generous, trustworthy, and wise at a significant level. Young/clever just fails to reach significance. Happy is linked with generous and trustworthy, stupid with untrustworthy and foolish, generous with trustworthy, and trustworthy with wise.

Finally, in view of the possibility that the imbalance of the sexes among the Ss might have influenced the distribution of some of the scores, a comparison was made between the distributions of the male/female attribute among the male and female Ss. The average number of times female was used by the 14 female Ss proved to be 6.51 . With the 27 male Ss, the figure was scarcely different at 6.66 .

\section{DISCUSSION}

In general, it would seem that people act in a fairly regular and statistically predictable way in attributing characteristics

Table 3

Raw Differences and Their Significance, by Feature and Attribute. The Difference is the Same Irrespective of whether it is Calculated upon the One or the Other of the Complementary Pair which Comprise the Attribute.

\begin{tabular}{|c|c|c|c|c|c|c|c|c|}
\hline & Male & Young & Happy & Stupid & Generous & Trustworthy & Wise & $\begin{array}{l}\text { Mean } \\
\text { Difference }\end{array}$ \\
\hline Eyes High & 215 & 193 & 232 & 194 & 212 & 201 & 133 & regardless \\
\hline Eyes Low & 170 & 156 & 68 & 172 & 139 & 158 & 135 & of sign \\
\hline Difference & $45^{*}$ & $37^{*}$ & $164 * *$ & 22 & $73 * *$ & $43^{*}$ & 2 & 55.14 \\
\hline Nose Short & 180 & 203 & 206 & 180 & 216 & 192 & 128 & \\
\hline Nose Long & 205 & 146 & 94 & 186 & 135 & 167 & 140 & \\
\hline Difference & -25 & $57^{* *}$ & $112 * *$ & -6 & $81 * *$ & 25 & -12 & 45.43 \\
\hline Mouth Narrow & 160 & 205 & 146 & 161 & 156 & 191 & 154 & \\
\hline Mouth Wide & 225 & 144 & 154 & 205 & 195 & 168 & 114 & \\
\hline Difference & $-65 * *$ & $61 * *$ & -8 & $-44^{*}$ & $-39 *$ & 23 & $40^{*}$ & 40.00 \\
\hline Eyes Wide & 186 & 180 & 152 & 183 & 187 & 191 & 131 & \\
\hline Eyes Narrow & 199 & 169 & 148 & 183 & 164 & 168 & 137 & \\
\hline Difference & -13 & I I & 4 & 0 & 23 & 23 & -6 & 11.43 \\
\hline $\begin{array}{l}\text { Mean Difference } \\
\text { Ignoring Sign }\end{array}$ & 37 & 41.5 & 72 & 18 & 54 & 28.5 & 15 & \\
\hline
\end{tabular}

* Significant at $p<.05$, by reference to the binomial probability distribution.

* Significant at $p<.01$. 
Table 4

Differences, Corrected for Number of Charcterizing Cards, for the Seven Significantly and for One Nonsignificantly Characterized Attribute.

\begin{tabular}{|c|c|c|c|c|c|c|}
\hline \multirow[b]{2}{*}{ Happy } & \multicolumn{3}{|c|}{$8,8 \mathrm{cards}$} & 4,4, cards & \multicolumn{2}{|l|}{ 2, 2 cards } \\
\hline & $\begin{array}{l}\text { (a) } \\
\text { (b) }\end{array}$ & $\begin{array}{l}\text { Eyes High } \\
\text { Nose Short } \\
\text { Mean }\end{array}$ & $\begin{array}{l}20.50 \\
14.00 \\
17.25\end{array}$ & (a)+(b) & 34.5 & \\
\hline Generous & $\begin{array}{l}\text { (a) } \\
\text { (b) } \\
\text { (c) }\end{array}$ & $\begin{array}{l}\text { Eyes High } \\
\text { Nose Short } \\
\text { Mouth Wide } \\
\text { Mean }\end{array}$ & $\begin{array}{r}9.13 \\
10.13 \\
4.88 \\
8.05\end{array}$ & $\begin{array}{l}(a)+(b) \\
(a)+(c) \\
(b)+(c) \\
\text { Mean }\end{array}$ & $\begin{array}{l}19.25 \\
14.00(\mathrm{a})+(\mathrm{b})+(\mathrm{c}) \\
15.00 \\
16.08\end{array}$ & 24.50 \\
\hline Young & $\begin{array}{l}\text { (a) } \\
\text { (b) } \\
\text { (c) }\end{array}$ & $\begin{array}{l}\text { Eyes High } \\
\text { Nose Short } \\
\text { Mouth Narrow } \\
\text { Mean }\end{array}$ & $\begin{array}{l}4.13 \\
7.13 \\
7.63 \\
6.30\end{array}$ & $\begin{array}{l}\text { (a)+(b) } \\
(\mathrm{a})+(\mathrm{c}) \\
\text { (b) }+(\mathrm{c}) \\
\text { Mean }\end{array}$ & $\begin{array}{l}11.75 \\
12.25(a)+(b)+(c) \\
14.75 \\
12.98\end{array}$ & 15.00 \\
\hline Male & $\begin{array}{l}\text { (a) } \\
\text { (b) }\end{array}$ & $\begin{array}{l}\text { Eyes High } \\
\text { Mouth Wide } \\
\text { Mean }\end{array}$ & $\begin{array}{l}5.63 \\
8.13 \\
6.88\end{array}$ & (a)+(b) & 13.75 & \\
\hline Wise & & Mouth Narrow & 5.00 & & & \\
\hline Stupid & & Mouth Wide & 5.50 & & & \\
\hline Trustworthy & & Eyes High & 5.38 & & & \\
\hline Stupid & $\begin{array}{l}\text { (a) } \\
\text { (b) } \\
\text { (c) }\end{array}$ & $\begin{array}{l}\text { Eyes High } \\
\text { Eyes Wide } \\
\text { Nose Long } \\
\text { Mean }\end{array}$ & $\begin{array}{l}2.75 \\
0.00 \\
0.75 \\
1.17\end{array}$ & $\begin{array}{l}\text { (a) }+(b) \\
(a)+(c) \\
(b)+(c) \\
\text { Mean }\end{array}$ & $\begin{array}{l}2.75 \\
3.50(a)+(b)+(c) \\
0.75 \\
2.33\end{array}$ & 1.00 \\
\hline
\end{tabular}

to certain outline features. Happiness, generosity, and youth, either despite or because of their overlap in a halo effect, are seen to be characterized by a reduced forehead and short nose. Mouth-width appears to have a significant but differential effect. When independently significant features appear in combination, there is a lawful and predictable increase in characterizing responses. This approximates, though falls somewhat short from, the ideal response patterns were human Ss perfoctly regular in processing information. Nevertheless, the empirical data was found to fit the theoretical curves remarkably closely. In both cases, the slope of the curves was found to be a function of two factors. One is the total number of features which together can characterize an attribute-the more there are, the lower the origin and the less steep the slope. Related to this is the point that the lower the characterizing value of any features taken singly, then again the lower the origin and the less steep the slope. Indeed, the more operative features there are, the less strongly will each one act in isolation, as there is a greater probability of competition arising from the co-presence of the converse of its fellows. Fundamentally, therefore, the operative strength of the feature determines the slope. This itself can be either the result of interaction with other features or simply the value Ss are found empirically to place upon it. Thus, the curve for stupid is found to be low and flat throughout.

It was noticeable that a very considerable overlap existed between the attributes wise/foolish and clever/stupid, both in terms of the halo effect, and the fact that mouth-width was found to be a significant-the only significant-distinguishing feature in both cases. It was considered a priori likely that there would be this overlap, despite possible conceptual differences. It is difficult, however, to see why there should be this stereotypical linking of mouth-width with wisdom and cleverness. Conversely, the almost universal folk connection between these two attributes and brow-height was completely unsupported. Just as eye-width was found to be completely neutral throughout, eye-height had no effect upon judged intellectual ability. It is of course possible, with eye-width, that its complete lack of characterization was a result of insufficiently drawn differentiation between the two extremes.

A similar lack of confirmation of a popularly held stereotype was the nonsignificance, and trend relationship. only, between trustworthiness and eye-width. The narroweyed figure was seen as only marginally less trustworthy than its converse. In fact, the only significant indicator of trustworthiness was eye-height. Stimuli with small brows were seen as just significantly more trustworthy than those with large ones.

A descending order of importance was found, from eye-height down to eye-width, in degree to which they tended to characterize certain attributes. Brunswik and Reiter (1937) found in their study that mouth-width was the most important single feature, while in the present study, though it tied top with eye-height for the greatest number of associated

Table 5

Halo Effects. Observed and Expected Seores for each Pair of Attributes. Expected Observed

\begin{tabular}{llll} 
Male Old, Female Young & 324 & 366 & $* *$ \\
Male Happy, Female Sad & 323 & 330 & N.S. \\
Male Stupid, Female Clever & 335 & 359 & N.S. \\
Male Generous, Female Mean & 332 & 335 & N.S. \\
Male Untrustworthy, Female Trustworthy & 322 & 343 & N.S. \\
Male Foolish, Female Wise & 338 & 343 & N.S. \\
Young Happy, Old Sad & 326 & 403 & $* *$ \\
Young Clever, Old Stupid & 326 & 349 & N.S. \\
Young Generous, Old Mean & 329 & 367 & $* *$ \\
Young Trustworthy, Old Untrustworthy & 330 & 369 & $* *$ \\
Young Wise, Old Foolish & 324 & 354 & $*$ \\
Happy Clever, Sad Stupid & 331 & 333 & N.S. \\
Happy Generous, Sad Mean & 326 & 437 & $* *$ \\
Happy Trustworthy, Sad Untrustworthy & 325 & 405 & $* *$ \\
Happy Wise, Sad Fooliah & 333 & 334 & N.S. \\
Stupid Mean, Clever Generous & 325 & 339 & N.S. \\
Stupid Untrustworthy, Clever Trustworthy & 324 & 364 & $* *$ \\
Stupid Foolish, Clever Wise & 335 & 492 & $* *$ \\
Generous Trustworthy, Mean Untrustworthy & 330 & 443 & $* *$ \\
Generous Foolish, Mean Wise & 332 & 337 & N.S. \\
Trustworthy Wise, Untrustworthy Foolish & 322 & 350 & $*$ \\
\hline
\end{tabular}

* Difference (d) $O-E$ is significant at $p<.05$ when $d>25$.

$* *$ It is significant at $p<.01$ when $d>33$, by reference to the normal approximation to the binomial probability distribution. 
significant differences, it came third in the scale oi overall mean differences. (ertainly the mouth is likeiy to be one of the most decisive faclal features in determining our judgments in view of its mobility and use in both vorbal and expressive communication.

There is a further problem as to why certain attributes were over-employed with under-employment of their converses. Thus a significant majority of cards were scen representing foolish males who were trustworthy, sad, and generous, in that order of strength. It is possible that a $S$ population consisting of entirely young, student, and predominantly male persons accounts for this. A comparison using a sample drawn from an entirely different population would be worthwhile. Nevertheless, analysis showed that the male and female Ss did not differ in their allocation ratios of the male and female categories where it might be expected that they would be most likely to differ.

With one exception, the halo effect was seen to link together all those attributes likely to be considered good, as separate from all the potentially bad ones. Thus, young, happy, generous, trustworthy, wise, and clever all tended in varying degrees to go together. The one exception, and a highly significant one, linked male with old and female with young. As a further check against the possibility of artifacts arising from the difference in sexes among the $S s$, values for male/old, female/young vs male/young, female/old were computed for both male and female Ss. No significant difference was found, a ratio of 1.27 being obtained with the feriales and one of 1.31 with the males. Consequently, it must be concluded that both sexes saw male and old, and female and young as going together.

\section{REFERENCES}

BROOKS, V.\& HOCHBERG, J. A psychophysical study of cuteness. Perceptual \& Motor Skills, 1960, 11, 205.

BRUNSWIK, L, \& REITER, L. Eindrucks Charactere schematisierter Gesichter. Zeitschrift für Psychologie. 1937, 142,67134

HERSHENSON, 1, KESSEN, $w_{,}$\& MLNSINGER, H, pattern perception in the human newborn; a close look at some positive and negative results. In W. Wathen-Dunn (Ed.), Models for the perception of speech and visual form. Cambridge, Mass. M.I.T. Press, 1967.

SAMUELS, M. R. Judgment of faces. Character \& Personality, 1939, 8, 18-27.

SECORD, P. F. Facial features and inference processes in interpersonal perception. In R. Tagiuri and L. Petrullo (Eds.), Person perception and interpersonal behavior. Stanford, Calif.: Stanford University Press, 1958.

SECORD, P. F., \& MUThARD, J. Personalities in faces: IV A descriptive analysis of the perception of women's faces, and the identification of some physiognomic determinants. Journal of Psychology, 1955, 39, 269-278.

SHELDON, W. H., \& TUCKER, W. B. The varieties of human physique. New York: Harper, 1940.

\section{NOTE}

1. Address: Department of Psychology, Monash University, Clayton, Victoria 3168, Australia,

(Accepted for publication January 6, 1969.) 